\title{
A Tekoá Ka'aguy Porã: Espaço Ancestral e Produção de Subjetividade Mbya-Guarani
}

\author{
João Maurício Farias ${ }^{1}$ \\ Inês Hennigen ${ }^{1}$ \\ ${ }^{1}$ Universidade Federal do Rio Grande do Sul, RS, Brasil. ${ }^{1}$ Universidade Federal do Rio Grande do Sul, RS, Brasil.
}

\begin{abstract}
Resumo: Neste artigo trazemos algumas discussões apresentadas na dissertação "Retomada Mbya-Guarani no Yvyrupá: produção de subjetividade, agenciamentos e criação de estratégias de luta", que teve como objetivo pesquisar processos de subjetivação, produção de composições e estratégias de enfrentamento/resistência em meio ao movimento dos indígenas Myba-Guarani de retomada de área em Maquiné-RS, Brasil. Entendeu-se que, para tanto, o método da cartografia se mostrava interessante, pois propicia traçar os percursos dos atores sociais no terreno da experiência. A partir de análise de materiais como diários de campo, fotos produzidas por indígenas e postadas em um grupo de WhatsApp que agregava apoiadores, audiovisuais de divulgação veiculados na internet, abordamos aqui, um dos pontos desenvolvidos na dissertação: o espaço sociocosmológico Mbya que se atualizou naquela região - a tekoá Ka'aguy Porã - entendendo-o como espaço ancestral (retomado na Retomada) para a efetuação do modo de vida - o tekó - Mbya-Guarani. Buscamos traçar aproximações, articulações e torções conceituais para pensar a produção de subjetividade deste povo indígena. Ao final, tecemos considerações sobre o que entendemos ser potentes aberturas e contribuições para a Psicologia Social, assim como para as ciências sociais e para a pesquisa com povos indígenas.
\end{abstract}

Palavras-chave: Tekoá; Tekó, Produção de subjetividade, Mbya-Guarani, Cartografia.

\section{The Tekoá Ka'aguy Porã: Ancestral Space and Mbya-Guarani Subjectivity Production}

\begin{abstract}
In this articlewe present some discussions derived from the dissertation "Mbya-Guarani Retrieval in Yvyrupá: production of subjectivity, agency and creation of strategies of struggle”, whose objective was to investigate subjectivation processes, production of coping/resistance strategies of the Myba-Guarani natives in the area of Maquiné/RS, Brazil. It was understood that, for this, the method of cartography was interesting, since it allows tracing the paths of social actors in the field of experience. Based on an analysis of materials such as field diaries, indigenous photos posted in a WhatsApp group that aggregated supporters, broadcasting aids on the Internet, we approach here one of the points developed in the dissertation: the Mbya sociocosmological space that was updated in that region-the tekoáKa'aguyPorã -understanding it as ancestral space (taken up in the Retrieval) for the realization of the way of life - the tekó Mbya-Guarani. We seek to draw approximations, articulations and conceptual twists to think about the production of subjectivity of this indigenous people. In conclusive terms, we make considerations about what we understand to be potent openings and contributions to social psychology, as well as to the social sciences and to research with indigenous peoples.
\end{abstract}

Keywords: Tekoá, Tekó, Subjectivity production, Mbya-Guarani, Cartography. 


\title{
La Tekoá Ka'aguy Porã: Espacio Ancestral y Producción de Subjetividad Mbya-Guaraní
}

\begin{abstract}
Resumen: En este artículo traemos algunas discusiones presentadas en la disertación "Retomada Mbya-Guaraní en Yvyrupá: producción de subjetividad, agenciamientos y creación de estrategias de lucha" que tuvo como objetivo investigar procesos de subjetivación, producción de composiciones y estrategias de afrontamiento/resistencia en medio del movimiento de los indígenas Myba-Guarani de retomada de área en Maquiné/RS, Brasil. Se entendió que, para tanto, el método de la cartografía se mostraba interesante, pues propicia trazar los recorridos de los actores sociales en el terreno de la experiencia. A partir de análisis de materiales como diarios de campo, fotos por indígenas y publicadas en un grupo de WhatsApp que agregaba apoyadores, audiovisuales de divulgación vehiculados en internet, abordamos aquí uno de los puntos desarrollados en la disertación: el espacio sociocosmológico Mbya que se actualizó en aquella la tekaá Ka'aguy Porã - entendiéndolo como espacio ancestral (retomado en la Retomada) para la realización del modo de vida - el tekó - Mbya-Guaraní. Buscamos trazar aproximaciones, articulaciones y torsiones conceptuales para pensar la producción de subjetividad de este pueblo indígena. Al final, hacemos consideraciones sobre lo que entendemos ser potentes aperturas y contribuciones a la psicología social, así como a las ciencias sociales ya la investigación con pueblos indígenas.
\end{abstract}

Palabras clave: Tekoá, Tekó, Producción de subjetividad, Mbya-Guaraní, Cartografía.

\section{Introdução}

Este artigo apresenta um dos pontos de discussão que desenvolvemos na dissertação "Retomada Mbya-Guarani no Yvyrupá: produção de subjetividade, agenciamentos e criação de estratégias de luta", fruto de pesquisa que teve como objetivo pesquisar processos de subjetivação, produção de composições e estratégias de enfrentamento/resistência em meio ao movimento dos indígenas Myba-Guarani de retomada de área em Maquiné/RS, Brasil.

O foco de nossa discussão aqui é o espaço sociocosmológico Mbya que se atualizou naquela região - a tekoá Ka'aguy Porã - entendendo-o como espaço ancestral (retomado na Retomada) para a efetuação do modo de vida - o tekó - Mbya-Guarani. Cabe comentar que, enquanto as atividades de campo foram realizadas pelo mestrando para a produção de sua dissertação, aqui o primeiro autor, este artigo foi construído em conjunto com sua orientadora, segunda autora. O campo foi realizado durante quase dois anos no acompanhamento com o movimento realizado por famílias indígenas Mbya-Guarani, intitulado Retomada no Yvyrupá, em área da mata Atlântica, no município de Maquiné, litoral norte do Rio Grande do Sul.
Essa área de 367 hectares, com $80 \%$ de mata nativa, estava sob posse e propriedade do Estado do Rio Grande do Sul, e servia como sede de unidade de pesquisa da Fundação de Pesquisa Agropecuária (Fepagro), extinta em novembro de 2016 pelo governo estadual, tendo sido retomada por famílias Mbya-Guarani em 27 de janeiro de 2017. Tal Retomada foi sendo efetuada a partir de articulações entre os indígenas e apoiadores, juruás - aqueles que são os não indígenas, entre eles: pesquisadores em antropologia, historiadores, geógrafos, cientistas sociais, professores estaduais e federais, ambientalistas, agrônomos, sociólogos, operadores do direito e moradores da localidade, entre outros.

O mestrando-pesquisador tinha inserção em campo com os povos indígenas no sul do Brasil desde o ano de 2006 (por ter realizado disciplinas, como etnologia indígena, na graduação em Ciências Sociais), havia trabalhado como técnico e gestor na Fundação Nacional do Índio (Funai) durante mais de sete anos e, mesmo não mais nessa função, ainda mantinha bastante contato e proximidade com indígenas, entre os quais os Mbya-Guarani. Em função disso, foi convidado a se envolver no apoio a este movimento logo nos primeiros dias de sua deflagração. Esta expe- 
riência logo se tornou muito interessante para a realização da pesquisa de mestrado que havia iniciado. Passa, então, a interagir com os indígenas como um de seus apoiadores e também na condição de um pesquisador implicado.

Entendemos que a possibilidade da realização desta pesquisa sobre a produção de subjetividade de um povo indígena, como os Mbya-Guarani, assim como a relação deste tema com a criação de estratégias de luta e criação de resistências mostrava-se de grande importância para a Psicologia. Nesta área do conhecimento havia um número muito limitado de pesquisas com povos indígenas de modo geral; especificamente sobre a produção de subjetividade, a singularidade destes povos, e as relações disso com as micropolíticas não encontramos estudos. Além disso, os indígenas, como grupos minoritários, têm enfrentado situações por demais dramáticas nas suas relações cotidianas com a sociedade envolvente e com o Estado nacional, que os coloca na resistência contra práticas genocidas e etnocidas, algo que necessita ser mais visibilizado e estudado. Assim, este tipo de pesquisa reveste-se de altíssima relevância para o campo da Psicologia Social e institucional, colocando-se também como uma contribuição, desta, para com outras ciências sociais e outras áreas envolvidas nas políticas públicas com e para os povos indígenas.

\section{Cartografia enquanto uma metodologia em processo}

Partimos da convicção de que uma metodologia interessante para esta pesquisa seria a que pudesse contribuir para traçar os percursos dos atores sociais em campo, suas estratégias, suas formas de se colocar; propiciasse traçar os encontros entre os indígenas e seus apoiadores, e também os encontros com atores que se colocavam contrários à permanência dos indígenas na área; viabilizasse acompanhar, no cotidiano vivo dos embates, como se davam as composições entre os atores e suas relações com espaços, tempos, tecnologias. Enfim, que permitisse traçar o percurso, os caminhos, o guatá - o caminhar - do pesquisador em campo e sua implicação com o indigenismo.

A partir disso, a cartografia despontou como método aberto e potente para a realização da pesquisa. Nesse contexto, o conhecer e o fazer seriam inseparáveis, o ato de pesquisar também seria ato de intervenção e toda a pesquisa seria uma intervenção. Sendo que "a intervenção sempre se rea- liza por um mergulho na experiência que agencia sujeito e objeto, teoria e prática, num mesmo plano de produção ou de coemergência - o que podemos designar como plano de experiência", de acordo com Passos e Barros (2015, p. 17). No fazer da pesquisa implicada, não há distanciamento do pesquisador e de seu objeto de pesquisa. A análise vai sendo construída ao se mergulhar na experiência coletiva em que tudo e todos estão sendo implicados. Para estes autores, a cartografia traz o conceito de implicação, que vai tomar o lugar dos conceitos de "transferência e contratransferência institucionais, radicalizando a crítica à neutralidade analítica e ao objetivismo cientificista" (Passos, \& Barros, 2015, p. 20). O observador estaria sempre implicado no campo da observação e sua observação também já seria uma intervenção que modificaria o próprio objeto.

Assim, a Retomada no Yvyrupá se apresentou como um plano de coemergência de relações de forças sobre relações de forças em agenciamentos e composições, sendo o plano de experiência deste pesquisar.

Para compor a pesquisa trouxemos materiais de campo inscritos na memória dos afetos e afecções, alguns fatos/atos transcritos em diário de campo; decupagens de pequenos vídeos documentários produzidos por indígenas, apoiadores ou jornalistas que os entrevistaram, principalmente durante o período inicial e de consolidação da Retomada, utilizados para divulgação deste movimentar-se dos Mbya-Guarani. Além disso, utilizamos relatos e relatórios de reuniões públicas na tekoá, assim como impressões aventadas em conversas do cotidiano. Lançamos mão, igualmente, de imagens, na maior parte fotografias realizadas pelos próprios indígenas, conversas e informações postadas no grupo de WhatsApp, nominado de Retomada no Yvyrupá, que congregava indígenas e apoiadores. Por fim, foram utilizados também, para as análises, documentos elaborados por grupos de pesquisadores, técnicos e indigenistas. Neste artigo referimos só parte destes materiais.

Ao longo do processo de pesquisa e análise, muitos pontos, em uma plural e rica rede, foram se discernindo e, assim, discutidos na dissertação; entre eles, foi sendo possível perceber um pouco do que os Mbya-Guarani apontavam sobre o que seriam as melhores condições para a realização e efetuação de seu tekó e sua tekoá na produção e reprodução da vida deste povo indígena, que passamos a abordar na sequência. 


\section{Resultados e discussões}

Inicialmente, nos parece importante trazer uma breve contextualização do povo e de expressões da língua Mbya-Guarani, observando que as tentativas de "traduções-definições" são, temos consciência, simplificações e, muitas vezes, estabelecem uma traição-restrição em face ao que a língua original, pelo seu dinamismo, experimenta entre seus membros.

Os Mbya-Guarani pertencem ao grupo linguístico Tupy, assim como os Nhandeva e os Kaiowa, e estão presentes na região centro-sul da chamada América do Sul desde antes das invasões dos portugueses e espanhóis no século XVI, onde vieram a se formar os Estados nacionais da Argentina, Paraguai, Bolívia, Uruguai e Brasil. Aqui, encontram-se, ainda no século XXI, principalmente no Rio Grande do Sul, Santa Catarina, Paraná, São Paulo, Rio de Janeiro e Espírito Santo, sendo que há famílias em alguns outros estados regionais brasileiros.

Para os Mbya, as palavras são carregadas de forças e sentidos incomensuráveis. Muitas vezes, ao exporem seus pensamentos, dizem que as palavras seriam inspiradas pelo coração, inspiradas por suas divindades e seus ancestrais. Assim, Tekoá significaria espaço, lugar que tem as condições de existência e realização de seu modo de vida ancestral, seu nhanderekó ou tekó - éo lugar onde se dão as condições do ser Guarani. Tekó, então, seria o modo de ser, modo de estar, sistema, lei, cultura, norma, comportamento, hábito, condição, costume - modo de ser esse com orientação profundamente religiosa, como aponta Pissolato (2007). Nhanderekó, palavra relacionada à última, seria o modo de ser ensinado e orientado por Nhanderú Tenondé e Nhandexi, respectivamente, grande pai criador do mundo e grande mãe protetora. Este mundo teria sido criado para seus filhos, os Mbya. Tal designação aos integrantes deste povo teria substituído "a designação anterior Ka'aguy, cuja tradução pode ser 'os que habitam as matas' utilizada para fazer referência aos grupos guarani refugiados nas matas das fronteiras em processo de definição, entre Brasil, Argentina e Paraguai" (Gobbi, Baptista, Printes, \& Cossio, 2010, p. 21).

Podemos perceber um pouco a relação entre estas palavras ao atentar para o nome que as famílias indígenas Mbya, ao retomarem esta porção da mata Atlântica em Maquiné, deram para a sua tekoá: Ka'aguy Porã, que designa "matas sadias, boas, com recursos naturais ainda abundantes, onde vivem os animais originais em sua diversidade" (Gobbi et al., 2010, p.21), ou, também, a grande mata sagrada.

Logo no início do ingresso na área, os indígenas nomearam seu movimento de Retomada no Yvyrupá, palavra cuja significação é dada nos seguintes termos:

É a expressão utilizada em guarani para designar a estrutura que sustenta o mundo terrestre, e para nós seu significado evoca o modo como sempre ocupamos o nosso território de maneira livre antes da chegada dos brancos, quando não existiam as fronteiras (municipais, estaduais e federais) que hoje separam nosso povo (Comissão de Terras Guarani Yvyrupá, 2018).

Para podermos pensar no diálogo e nas relações entre tekoá e tekó como encontro de elementos, que conjugados, possibilitariam contribuir para o exercício da produção da subjetividade Mbya-Guarani, importante também trazermos a palavra guatá, que remete ao caminhar. O termo é utilizado pelos Mbya para o ato de andar, viagem, significando também "deslocar-se". Pode ser uma viagem xamânica na qual o xamã, através de seus saberes, "caminha" entre formas e domínios (Pradella, 2009). É possível entender que se trata de um andar que "guaraniza" o mundo, como fizeram suas divindades criadoras, Nhanderú Tenondé e Nhandexi. Assinale-se que este termo está ligado à intensa mobilidade (territorial) Mbya-Guarani, sendo essa uma prática ancestral muitas vezes confundida com certo nomadismo pelas sociedades nacionais envolventes, fator utilizado com frequência para destituí-los de direitos territoriais pelos Estados nacionais.

Feita esta aproximação-sensibilização, "guaranização", de nosso leitor a partir das palavras Mbya, seguimos, então, o percurso - o guatá - deste artigo, como seguimos o da pesquisa, quando foi apontado pelos Mbya da Retomada que aquela mata nativa era um lugar ótimo, privilegiado, que nutriria as melhores condições para a efetuação de uma tekoá, no caso a Ka'aguy Porã - grande mata sagrada - de seu povo.

$\mathrm{E}$, aquela área se constituindo enquanto uma tekoá, seria, portanto, o lugar sociocosmológico propício para a vivência de seu modo de ser e estar no mundo, de seu tekó ou nhanderekó. Estando estes indígenas em uma tekoá, experimentando o viver segundo seus ancestrais e suas divindades, estariam também mostrando para os juruá apoiadores - e 
igualmente para quem quer que de fato os escutasse - que esta Retomada no Yvyrupá oportunizaria a consecução do que se poderia chamar de produção de subjetividade Mbya-Guarani.

Foram várias as indicações dos indígenas neste sentido. Em vídeo de divulgação "Retomada Mbya Guarani em Maquiné”, postado em página da Associação de Estudos e Projetos com Povos Indígenas e Minoritários (AEPIM), em 2017, alguns dias após entrarem na área, André Benites ${ }^{1}$, indígena Mbya, em depoimento gravado (e transcrito por nós), diz:

Nós entramos aqui pra aprender, levar a vida, continuar nossa cultura, principalmente para o jovem, pra voltar, manter, porque esquece, ninguém esquece. Nós Guarani nunca esquece. Só que nós não temo mais condições pra viver como nós quer e porque tem muita aldeia, aldeia pequenininha que não tem nada, não tem árvore, não tem remédio, não tem água. Aldeia né, o que é aldeia, né? Não é só botar uma casinha e ficar ali né. Tekó, tekó é nosso modo de viver né, tekó é praticar nossa cultura, aprender, fazer remédio, ir pro mato, conhecer a nossa, manter as nossas semente, nosso ritual, tudo que tem esse tekó. Seria um lugar onde tem espaço pra manter nossa cultura, isso é tekoá e que todos conhece como aldeia, então se não sabe, se não, pensar uma aldeia é uma aldeia, não quer dizer nada. Pra nós significa muito forte esse tekoá. Falar de tekó, se nós pensar agora, nós tamo perdido, se nosso antepassado vivia por aqui né, a gente sabe não é, a gente não inventa que diz que é próprio daqui, que tem funcionário que diz que no começo que reviravam a terra e achava umas cerâmica, pedaço de cerâmica (Aepim, 2017).

A partir do que André Benites fala em tekó como modo de vida Mbya, é possível fazermos uma aproximação conceitual e trazer elementos que pensadores como Guattari e Rolnik (1986) colocaram sobre produção de subjetividade.

A subjetividade está em circulação nos conjuntos sociais de diferentes tamanhos: ela é essencialmente social, é assumida e vivida por indivíduos em suas existências particulares. O modo pelo qual os indivíduos vivem essa subjetividade oscila entre dois extremos: uma relação de alienação e opressão, na qual o indivíduo se submete à subjetividade tal como a recebe, ou uma relação de expressão e de criação, na qual o indivíduo se reapropria dos componentes da subjetividade, produzindo um processo que eu chamaria de singularização (Guattari, \& Rolnik, 1986, p. 33).

Estamos tratando da explicitação que as lideranças indígenas estavam manifestando - e seguem fazendo, pois, apesar de algumas conquistas, enfrentamentos prosseguem - como a possibilidade de continuarem a se produzir enquanto singularidades Mbya. Não estamos tratando aqui de temas relativos ao possível sujeito Mbya-Guarani individuado e a sua dessemelhança da individuação do sujeito que experimenta a subjetivação capitalística. Estamos buscando traçar aproximação que o desejo de exercitar o tekó $\mathrm{e}$ o nhanderekó tem em relação à possibilidade da operação do que poderia ser um tipo de máquina de produção de subjetividade Mbya-Guarani.

Guattari e Rolnik (1986) vão dizer, ainda, que a subjetividade seria de uma natureza maquínica, fabricada, modelada, recebida, consumida.

As máquinas de produção de subjetividade variam. Em sistemas tradicionais, por exemplo, a subjetividade é fabricada por máquinas mais territorializadas, na escala de uma etnia, de uma corporação profissional, de uma casta. Já no sistema capitalístico, a produção é industrial e se dá em escala internacional (Guattari, \& Rolnik, 1986, p. 25).

Seria possível conceber que os povos indígenas, em especial os Mbya-Guarani, experimentam sua máquina social de autorreprodução com bases mais territorializadas do que as máquinas sociais capitalísticas. Porém, esta territorialização não pode ser vista como um tipo de sedentarização, um apego arcaico à terra ancestral, que estaria marcada geograficamente. Até porque estamos tratando de compreensões muito distintas de mundo, de cosmologias, de territórios e de territorialidades.

Sobre território, Silva (2013) escreveu que, para os Mbya, seria o espaço vivenciado, experimentado e

${ }^{1}$ Uma das principais lideranças deste movimento da Retomada no Yvyrupá. 
fruto de relações estabelecidas entre grupos de pessoas que compartilham uma identidade e bens simbólicos, que principalmente não haveria separação entre natureza e cultura, e que essas pessoas estabeleceriam relações constantes com as alteridades humanas e extra-humanas que compõe sua cosmologia. E, também, que os Mbya construiriam suas experiências de mundo, articulando "a memória de seus ancestrais com a recriação e reelaboração de suas tradições no cotidiano da atualidade" (Silva, 2013, p. 52).

Este antropólogo, ainda sobre a territorialidade Mbya-Guarani, disse que "do ponto de vista teórico, a territorialidade é aqui encarada enquanto interpenetração e inter-relação entre território, concepções cosmo-ontológicas, corporalidade, ideologias sobre a natureza, noção de pessoa e as redes de parentesco lançados sobre esta base territorial" (Silva, 2013, p. 53). O autor complementa pontuando que as relações entre humanos, não humanos, divindades, vivos e mortos norteariam o entendimento de como se conceber a territorialidade Mbya.

Portanto, território, para os Mbya, se apresenta para além das perspectivas espaço/temporais da nossa sociedade nacional (no caso, brasileira), tampouco se enquadra na perspectiva da propriedade privada e/ou estatal das sociedades capitalistas liberais. É um espaço do vivido e do vivenciado, onde a influência dos ancestrais se atualiza e as divindades e demiurgos se fazem presentes a cada instante. Há infinitas relações sendo experimentadas no exercício do território e na experiência da territorialidade que se efetuam em devires Mbya. Pesquisar a Retomada é dialogar com território existencial deste povo indígena no exercício de sua territorialidade dinâmica e em intenso movimento.

Como máquinas sociais territorializantes de caráter segmentário e despotencializador é possível apontar, na fala de André Benites mais acima, o "modo-aldeias" que, via de regra, é o oferecido aos indígenas pelos Estado nacional e/ou regionais, espaços que não permitiriam o viver Mbya-Guarani, o "negativo" do que experimentam na área da Retomada, onde os jovens teriam as melhores condições de vida para aprender e exercitar seu tekó.

Logo na primeira semana da Retomada, Cirilo Morinico $^{2}$ fala, em outro vídeo postado na internet, que "aqui tem toda a estrutura pra formar a vida do povo Mbya-Guarani, então tem estrutura, tem matéria prima, tem água boa, tem os passarinho cantando e isso dá alegria, dá harmonia pras crianças, pras mulheres e pros homens" (Guidoux, 2017).

Em reunião no dia 02 de abril de 2017 com um grupo de apoiadores, Cirilo Morinico, no centro da nova tekoá que estava sendo efetuada, falou sobre as condições desta área retomada e sua importância para a vida Mbya. Diz que é uma forma de caminhada dos Guarani, que os antigos caminhavam dessa forma, respeitando a natureza, respeitando os seres vivos, que os Mbya, após quase 600 anos de contato, vêm perdendo as condições de ter saúde, porque muitas vezes não conseguem as melhores formas de viver, que nesta área retomada tem plantas de remédios tradicionais. Recordou que ali podiam estar andando na mata nativa, rezar com suas divindades e com a natureza, e que nesta área haveria as possibilidades para exercer suas formas de vida e que por isso a chamariam de sua tekoá. Nesta reunião, Cirilo explicou que tekoá quer dizer que na área havia matéria-prima para construção de Opy e que isso formaria a vida do Mbya, que morar em áreas onde há muito eucaliptos, como na área da Companhia Estadual de Energia Elétrica (CEEE), cedida pelo governo anterior, não seria tekoá, não teria vida. E nesta Retomada teria tudo, não faltaria nada e que os seres da mata, como suas divindades, teriam pedido aos Mbya que retomassem esta área em Maquiné (Notas de Diário de Campo).

Neste sentido, entendemos que os Mbya-Guarani desta tekoá foram sinalizando para seus apoiadores, através de imagens fotográficas e pequenos audiovisuais postados no grupo de WhatsApp e em páginas de organizações apoiadoras, como AEPIM, Amigos da Terra Brasil, entre outras, que seu guatá no mundo de seus ancestrais e de suas divindades seria algo que poderíamos aproximar da noção de cuidado de si (Sales, 2008), um movimento de resistência criativa na luta por garantir seu tekó.

As principais lideranças Mbya da Retomada repetidamente manifestaram que esta área tinha relação com a sua ancestralidade, e que nela seria possível o exercício de seu tekó. E, que esse espaço sociocosmológico, teria água de boa qualidade, animais para caça, mato nativo, recursos para a produção de casas tradicionais, insetos, passarinhos, peixes e que, por apresentarem estas condições, serviria como sua tekoá.

${ }^{2}$ Outra liderança indígena muito envolvida no apoio à Retomada, apesar de residir em outra tekoá, a Nhetaguá, localizada no bairro Lomba do Pinheiro, em Porto Alegre-RS. 
Em um documento ${ }^{3}$ elaborado por técnicos e pesquisadores que passaram a apoiar a Retomada no Yvyrupá é citada fala de Cirilo Morinico, em que ele informa como os Mbya-Guarani estavam se sentindo em relação a esta área e a importância para sua cosmologia:

Água tem espírito, árvore tem espírito, então a gente se comunica com eles, pra gente entra, não entra assim. Pra usar qualquer coisa, nós entramo com ritual, com processo de respeitar, de uma forma que eles precisam também, precisam de respeito. Então é um lugar dos deus, é um lugar sagrado, que deus deu, indicou pra gente vir aqui. Então esse é o sonho dos Guarani Mbya, por isso que hoje estamo feliz (Printes, Gobbi, Farias, \& Soares, 2017, p. 3) ${ }^{4}$.

A etnógrafa Pissolato (2007) trata sobre as relações entre tekó e tekoá e a centralidade que esses elementos desempenham na maneira de viver dos Guarani em geral e quanto à mobilidade em particular. Cita Montoya, que dá ao termo tekóos seguintes significados: "ser, estado de vida, condição, estar, costume, lei, hábito" (Montoya, 1876, p. 363-7 apud Pissolato, 2007, p. 108). Assim, no "modo de ser" estariam contidos os "modos" de reciprocidade social, formas econômicas, o "modo religioso", tudo implicado numa dimensão concreta de espacialidade, que por sua vez, é traduzida pelo termo tekoá (Pissolato, 2007).

Pareceria haver um sistema, um tekó, que englobaria um tipo de ética religiosa, uma forma econômica, um código de solidariedade, enfim, uma orientação para estar no mundo deixada pelos ancestrais. Os Guarani buscariam formas de atualização de seu modo de vida, a despeito das grandes adversidades que enfrentam para o exercício de seu tekó.

O seu modo de ser, compreendendo tanto orientações para relações humanas ou a "reciprocidade" (trocas recíprocas entre famílias guaranis) quanto para o relacionamento dos humanos com o ambiente, teria no movimento, na mobilidade intensa uma forma de cuidar do território, conforme Ladeira (2001, p. 223 apud Pissolato, 2007, p. 210).

Portanto, nesse caminhar, nesse guatá, os Mbya buscariam o aperfeiçoamento que poderia manter as "boas" condições de vida terrena, condições que tornariam possível a continuidade da vida dos humanos, os Mbya, em um mundo percebido como imperfeito. Diz também, a partir de estudos clássicos, que a "forma genuína" da crença no paraíso como "aguyjê, perfeição espiritual e física" seguiria persistente entre os Mbya (Pissolato, 2007, p. 103). Este desejo do aguyjê se relaciona à busca da perfeição e de espaços que possibilitem o exercício de seu modo de vida, o tekóe, para isso, motivavam seu caminhar em busca de uma tekoá. É possível que o exercício e a manifestação do desejo da "busca da perfeição, da verdade verdadeira", o aguyjevete, que vimos manifesto ritualmente ou em conversas cotidianas na tekoá e no grupo de What$s A p p$, na atualidade, já fosse uma prática de agenciamento coletivo e de processo de subjetivação, ou de "guaranização" do mundo Mbya-Guarani.

Trabalhos de alguns etnógrafos apontam uma compreensão dos fenômenos migratórios para além de motivo mítico unicamente, interpretando os deslocamentos também como procura por lugares para a atualização de um "modo de vida" Guarani. Assim, além do significado religioso, buscariam a dimensão ecológica, econômica e social, entendida aqui, como "tradicional". Neste sentido, cabe discutir um pouco mais um aspecto fundamental da vida Mbya, que se relaciona intimamente com as noções de território e territorialidade, como tekó e tekoá, que é a sua intensa mobilidade, correlativo ao guatá. O antropólogo Pradella (2009) refere-se ao termo tanto para designar o caminhar (pelo território físico), o deslocar-se, bem como para referir uma viagem xamânica, em que o xamã transita entre formas e domínios das outras alteridades. Já Pissolato (2007) aborda vários aspectos sobre este guatá Mbya, se referenciado em estudos clássicos.

O fenômeno que contemporaneamente vem sendo chamado de mobilidade entre os subgrupos Guarani, e particularmente entre a população

\footnotetext{
${ }^{3}$ Intitulado “Informações Preliminares sobre os Mbya-Guarani no Município de Maquiné: Retomada de Terras Ancestrais-2017”.

${ }^{4}$ Este documento preliminar elaborado por pesquisadores indigenistas não foi publicado, tendo sido entregue para instituições como: Ministério Público Federal (MPF) em Capão da Canoa-RS, para a Presidência da Comissão de Direitos Humanos da AL-RS. Assim, o acesso ao mesmo pode ser obtido com os pesquisadores que o elaboraram ou com estas instituições aqui apontadas.
} 
Mbya, foi tratado na bibliografia etnohistóricas e etnológica sobre os Guarani a partir da percepção de uma articulação profunda entre movimentos territoriais e a religião, seja associando-os diretamente ao mito da "busca da terra sem mal", que se tornou tema clássico para os estudiosos dos Guarani desde a publicação das "Lendas da criação e destruição do mundo como fundamentos da religião dos Apapocuvá-Guarani", de Nimuendaju (\{1914\} 1987), ou a abordagem contemporânea do tekó - ou da busca de tekó -, tomado frequentemente como "modo de ser" com orientação profundamente religiosa (Pissolato, 2007, p. 98).

Esta autora entende que a intensa mobilidade pode ser apontada como um tipo de estratégia de preservação do nhanderekó, sendo os movimentos reconstruídos pela memória dos indígenas como forma de resistência às mais variadas ameaças e opressões ao exercício de seu tekó, de sua cultura ou ao seu modo de vida, apontado por Nhanderú. Ela expõe, ainda, que o sentido da palavra Yvymarãe'y como sendo "solo intacto, não edificado" (Melyà, 1981, p. 10-11 apud Pissolato, 2007, p. 107) traz implicações econômico-ecológicas nas formas de ocupação e na mobilidade territorial dos Guarani.

Sobre a busca de lugares para o exercício do tekó Mbya-Guarani e a relação disso com o exercício da tradição, Pissolato (2007) comenta que a tradição estaria no processo de busca, de procura e não na repetição pura e simples de normas e apontamentos de condutas do "ser" Mbya-Guarani. O caminhar - guatá - seria a tradição, mas o caminho há que ser inventado, criado a cada dia; a mobilidade como tradição, o caminhar como seus deuses e seus ancestrais fizeram ao "guaranizar" o mundo. Mundo e os Mbya na condição de imperfeição onde se busca a efetuação e atualização do aguyjê.

É possível encontrar indígenas deste povo sempre em movimento, em deslocamento, "caminhando" como suas divindades a "guaranizar" o mundo. Vale lembrar que estar em uma área indígena ou noutra, ou mesmo exercitando seu guatá, seria também já estar em sua grande terra do Yvyrupá, criada pelas divindades para que os Mbya pudessem usufruir neste mundo. Então, o deslocar-se de um lugar ao outro não seria, para estes indígenas, abandonar uma área, abandonar um território, mas exercitar sua terri- torialidade em busca do aguyjê, em busca de sua perfeição pessoal e do melhor lugar para viver o seu tekó.

De outra parte, esse deslocar-se, esse caminhar pelo mundo das divindades e dos ancestrais está ligado a uma de suas práticas socioambientais que possibilitaria a recuperação e renovação ambiental do lugar que era deixado, prática muito dificultada pelo avanço da colonização e das propriedades privadas, do modo de produção capitalístico e do agronegócio sobre as áreas indígenas.

O movimentar-se das famílias Mbya, na experiência da Retomada no Yvyrupá, está ligado a este guatá pelo mundo de seus ancestrais e de suas divindades. Não houve, ao menos explicitamente, manifestação sobre a busca da mitológica "terra sem males" dos Guarani, como motivação para sua Retomada. Porém, desde os primeiros dias, manifestavam muita satisfação por poder exercer sua religiosidade intensa, o que foi viabilizado a partir do contato cotidiano com os seres da mata, com suas divindades ali presentes, e "concretizado" com a construção de um de seus principais dispositivos sociocosmológicos, a Opy.

A possibilidade de construírem a Opy (Foto 1) está associada a vários elementos que a mata nativa da região oferecia, além da presença das divindades e de sua ancestralidade no presente. Para os Mbya-Guarani, os chamados recursos naturais não são simples recursos materiais, como a civilização ocidental os considera ao objetivar elementos da natureza, mas são impregnados de forças e conexões.

Apesar da Opy não ser um espaço exclusivo das relações entre os indígenas e suas divindades (elas se dão no cotidiano em todas as áreas da vida, principalmente em espaços de mata nativa como o retomado em Maquiné), na $O p y$ são realizados vários rituais

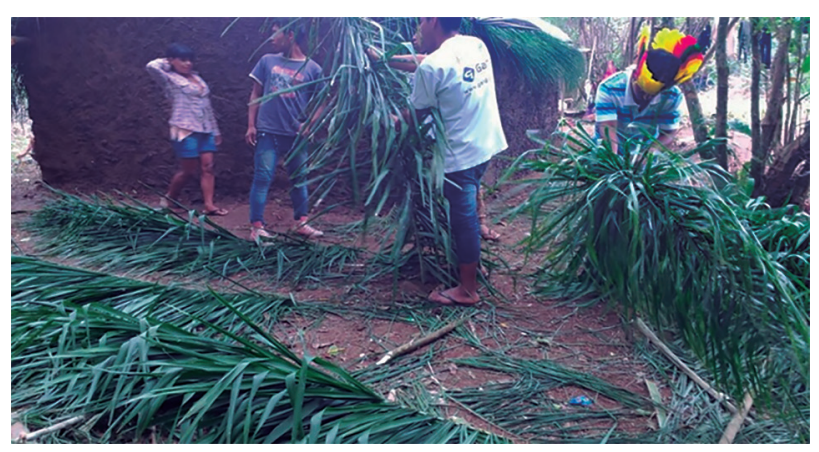

Foto 1.

Construção da Opy, feita por indígena e compartilhada via WhatsApp. 
bastante significativos, como o do Ka'a heté, da erva mate, que está relacionado ao novo ciclo anual de vida, o arapiau, que se realiza no início do período que chamamos primavera, e também o nhemongarai, ritual de batismo e de nominação Mbya-Guarani com o awati (milhos de tipos e cores variadas).

O primeiro autor, no passado, em aldeia situada em Araquari-SC, teve a oportunidade de experimentar um ritual de nhemongarai, onde algumas crianças e adultos receberam seus nomes Mbya. Após várias horas de danças, cantos, de uso do petynguá (cachimbo) com tabaco, do Karai recitar cantando os porahêi, esse último acabou por receber das divindades o nome a ser transmitido para as pessoas (indígenas e, eventualmente, alguns juruá). O nhemongarai ocorre normalmente no início da colheita de awati, entre os meses de dezembro e janeiro de cada ano. Segundo o que manifestou um indígena Mbya da Retomada no Yvyrupá, em uma caminhada pela mata junto com um grupo de juruá que visitavam a nova tekoá, cada cor de grãos do awati estaria ligada a uma das principais classes de nomes celestiais (Notas do Diário de Campo).

Na Foto 2 é possível ver indígenas jovens ao retornarem da mata nativa, após caçarem tatus; junto com um pequeno vídeo, ela foi compartilhada por Tiago, indígena, genro de André Benites, no grupo do WhatsApp, em um domingo chuvoso do inverno de 2017. A postagem de materiais como esses demonstravam a relação dos indígenas com a mata nativa e as qualidades do local para o exercício do modo de vida ancestral, confirmando o que já estavam sinalizando nos vídeos iniciais, a convicção de tratar-se de lugar pleno das condições para a efetuação de sua tekoá, para se autoproduzirem como Mbyas. As fotos e vídeos enviados também serviam como um presente aos juruá que os apoiavam e aos que estavam se aproximando da rede de apoiadores. Assinalamos, assim, a existência de agenciamentos ${ }^{5}$ em operação, algo da ordem de um processo de subjetivação, de guaranização dos juruá apoiadores.

Da mesma forma que a caça, a possibilidade de praticarem a pesca (Foto 3), mais do que remetido ao objetivo de ato nutricional, permite a atualização de uma de suas práticas ancestrais de existência. Em vários momentos, os indígenas marcaram o fato de que haver naquela área águas limpas, águas correntes e presença de peixes para pescarem seria uma condição de qualidade de uma boa terra Mbya. Já usarem camisas do Grêmio ou do Internacional, como nesta foto, torcerem por times de futebol ou mesmo gostarem de jogar este esporte não os deixa mais nem menos indígenas Mbya-Guarani. A imagem do "idílico" indígena "puro" só faz impossibilitar uma existência indígena a ter de haver-se com plurais atravessamentos da sociedade envolvente.

Há muitos exemplares da árvore Pindó (Foto 4) na área da Retomada do Yvyrupá. Trata-se de árvore ligada à mitologia da criação do mundo Mbya, a primeira árvore, e serve de referência para indicar presença, no passado, de outros indígenas de seu povo na região onde se encontra. O Pindó serve para dar sus-

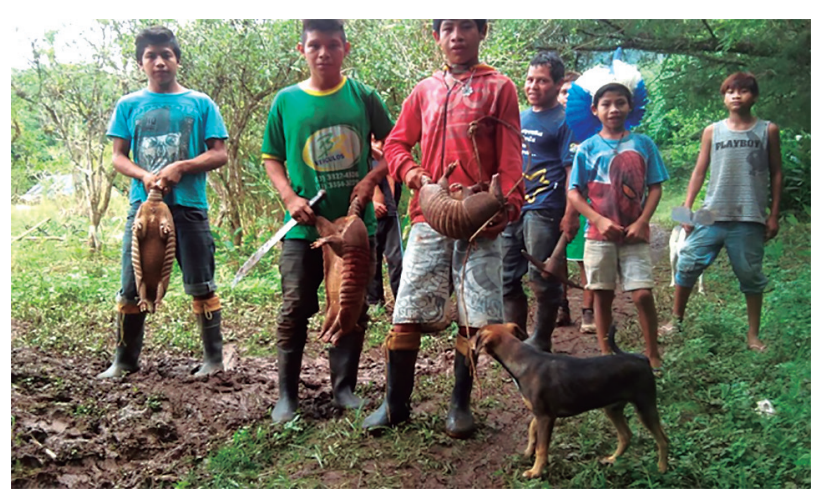

Foto 2.

Caçada na mata nativa; feita por indígena e compartilhada via WhatsApp.

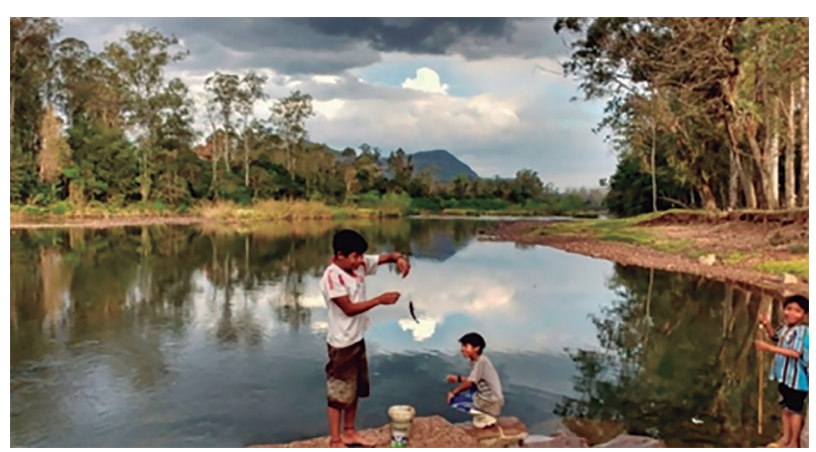

Foto 3.

Pesca em rio próximo à área da Retomada; feita por indígena e compartilhada via WhatsApp.

${ }^{5} \mathrm{O}$ conceito de agenciamento e também o de guaranização foram trabalhados na dissertação, principalmente quando foram analisadas questões relativas aos encontros entre apoiadores e indígenas neste território existencial da Retomada no Yvyrupá. Sugerimos acessar a dissertação completa para conhecer a discussão. 
tentação e base para a construção da Opy e também para o mundo celestial, uma vez que se espalha pelos pontos cardiais. O contato com esta árvore mitológica e com a mata nativa parece permitir também o contato direto com suas divindades e com os demiurgos de outros seres de sua cosmologia. Assim, a presença do Pindó pode ser considerada um referente forte de pertencimento e territorialização Mbya-Guarani nesta porção da Mata Atlântica.

Em encontro com visitantes na região retomada, André Benites, ao apontar para um Pindó cortado, comenta que essa árvore estaria aguardando uma vespa que ali colocaria seus ovos, as larvas então se criariam alimentando-se de sua árvore mitológica, produzindo assim o echó. De fato, após alguns meses, mulheres indígenas fazem sua coleta (Foto 5), que é farta, lota uma frigideira, sendo tostadas e, na sequência, os indígenas deliciaram-se com a gostosa iguaria.

A foto da coleta, assim como outras relacionadas a esta prática-ritual, foi feita e postada por mulheres indígenas, que, com isso, demonstram, ao mesmo tempo, ter boa noção de fotografia com celular e uma de suas importantes práticas de ser e estar Mbya-Guarani, de seu nhanderekó. Sobre a utilização de smartphones e mesmo de aplicativos como WhatsApp pelos indígenas, é importante trazermos alguns elementos para análise: os indígenas Guarani estão há mais de 500 anos em contato com a sociedade nacional/ envolvente, tanto brasileira como de países de língua espanhola, e, apesar de manterem hábitos e traços sociocosmológicos de sua tradição milenar e buscarem as melhores condições para vivenciar seu tekó, nunca se colocaram avessos à utilização de ferramentas tecnológicas dos juruá e/ou de algum outro povo indígena. Sua condição de indígena Mbya-Guarani não seria afetada pela utilização de um smartphone, no sentido de perda de sua cultura e de aculturação $0^{6}$, até porque os utilizam para comunicar-se com seus parentes indígenas e o fazem em sua própria língua.

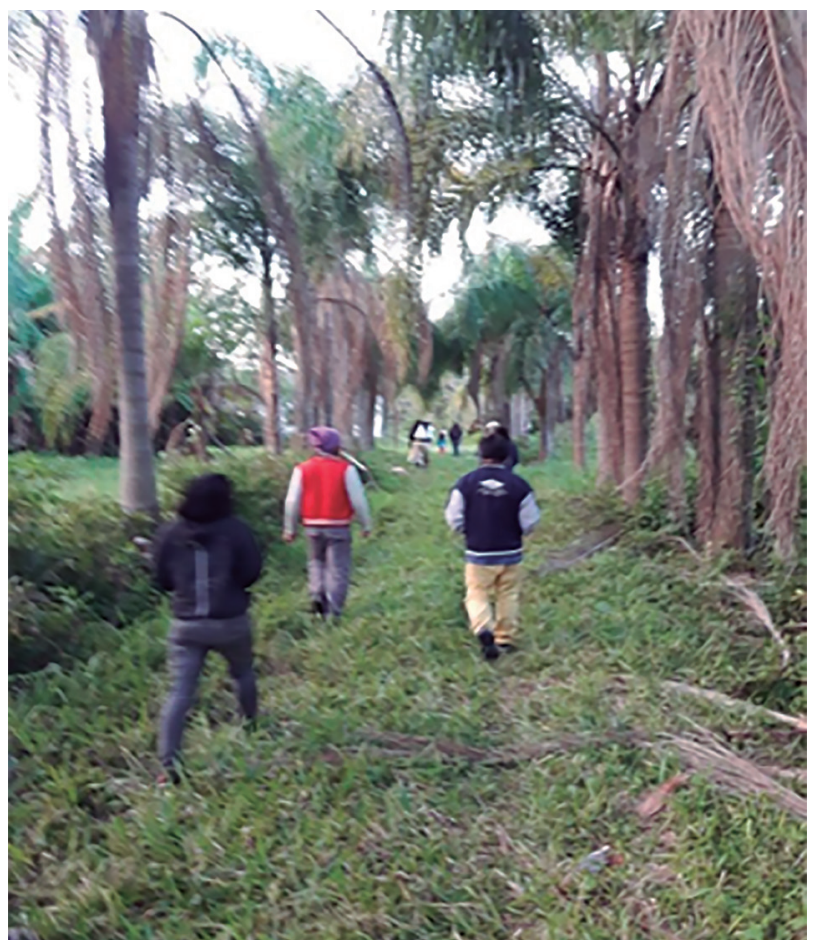

Foto 4.

Caminho de Pindós; feita pelo mestrando-apoiador.

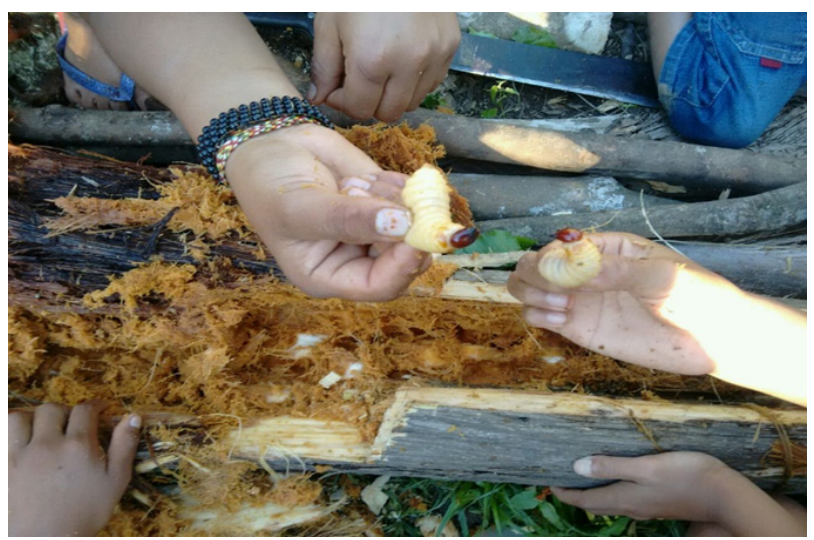

Foto 5.

Coleta de Echó por mulheres Mbya; feita por indígena e compartilhada via WhatsApp.

\footnotetext{
${ }^{6}$ A ideia de perda de cultura e de aculturação dos povos tribais e dos povos indígenas, através da utilização de elementos, dispositivos tecnológicos e/ou outros traços culturais de povos diferentes já foi ultrapassada na antropologia e na etnologia. Atualmente considera-se que estes povos nunca se colocaram no mundo como se tivessem elementos culturais imutáveis e que buscassem preservar suas tradições acima de tudo. A condição de conceber os indígenas com posição identitária fixa e parada no tempo é mais uma postura de setores da sociedade nacional para com eles, do que eles sobre si mesmo. Experimentar as mudanças de perspectiva e incorporar traços culturais de outros seres e povos, dando outros sentidos e significados, parece ser uma condição cotidiana dos povos ameríndios, na medida em que são povos que experimentam cotidianamente o exercício da alteridade com outros povos e com outros seres de sua cosmologia. Porém, há que se destacar que, mesmo não compreendendo que a utilização de dispositivos tecnológicos criados pelos juruá venha significar um processo de "aculturação", seria preciso pensarmos sobre o fato de que dispositivos tecnológicos não são dispositivos neutros, mas vetores de subjetivação, de semiotização a-significantes e que, na medida em que são produzidos/criados na perspectiva da máquina de produção de subjetividade capitalística, poderiam também estar provocando afetações aos indígenas, cuja discussão ultrapassa objetivo e objeto desta pesquisa.
} 
De outra parte, tem sido possível perceber a acurada sensibilidade de indígenas Mbya-Guarani para a produção fotográfica e audiovisual. Muitos documentários já foram produzidos por indígenas deste povo que estiveram fazendo formação em cinema com a organização não governamental (ONG) Vídeo nas Aldeias. Assim como vários jovens indígenas passaram, nos últimos anos, a utilizar intensamente as tecnologias de comunicação instantânea como Messenger, Facebook, WhatsApp e outros aplicativos, nem por isso deixam de se sentir e de se colocar no mundo como indígenas Mbya-Guarani.

Excetuando a fotografia do caminho de pindós, todas outras foram produzidas e postadas no grupo no WhatsApp pelos indígenas na nova tekoá. Ao associa-las - construção da $O p y$, caçada na mata nativa, pescaria no rio de águas cristalinas, caminho dos pindós, coleta do echó - temos vários elementos que, conjugados, qualificam a área como ancestral e propícia para o exercício do seu tekó. Aqui é possível pensar na ancestralidade não apenas como referência a um passado vivido e mitológico, mas como uma experiência de certa forma transtemporal, na qual passado, presente e futuro conjugam-se entre si. A presença destes elementos na mata nativa remete-os para a presença de seus ancestrais e de suas divindades no passado, mas também tanto seus ancestrais como suas divindades estão participantes no presente nesta tekoá Ka'aguy Porã. E, se tais elementos que contribuem para exercício de seu tekó e efetuação da sua tekoá estão presentes e podem se efetuar e atualizar no aqui e agora, também estariam presentes em um futuro possível. Condição de possibilidade de continuarem existindo no mundo criado por suas divindades, assim como condição da própria continuação da existência deste mundo.

Nesta atualização e na efetuação de mundos possíveis, os indígenas vão podendo experimentar certo reestabelecimento de processos de produção de subjetividades Mbya com este acontecimento da Retomada no Yvyrupá. Há uma produção semiótica Mbya-Guarani sendo atualizada e efetuada nesta experiência, neste acontecimento: ao compartilharem pelo grupo de WhatsApp, em um domingo chuvoso de inverno, fotos de indígenas jovens retornando da mata para o centro da tekoá com três tatus caçados; quando "apresentam" a larva echó, quando mostram que, ato contínuo à entrada, é com a construção da nova casa tradicional que se ocupam. Nestes momentos, estão dando visibilidade para elementos carregados de sentidos que dão conta da atualização de sua ancestralidade no aqui e agora. Um virtual que se atualiza. Um indígena que se produz e se semiotiza Mbya-Guarani.

Pensamos que, nesta Retomada, operam dois processos de semiotização, sendo um entre os próprios Mbya-Guarani, processo de semiotização no viver cotidiano, processo de semiotização do tekó Mbya, que também seria um processo de produção de subjetividade deste povo indígena, onde, segundo Lazzarato (2014), a eficácia semiótica do discurso não verbal seria formidável, porque afetaria primeiramente ao corpo, que é preciso educar, moldar, seria a própria carne como molde de espírito. E outro, que seria um processo de semiotização com os juruá, que vai no sentido de mostrarem-se para os aliados, e assim experimentarem com estes juruá um novo processo de subjetivação, neste caso de composição de aliança. Um processo semiótico de guaranização e de produção de aliados.

A Retomada no Yvyrupá é produtora de pequenas e grandes afecções corpóreas e incorpóreas. A Retomada vai acontecendo em todos os espaços, em todas as relações, em todas as vidas envolvidas direta e indiretamente, pelas redes em que os temas deste acontecimento vão sendo trabalhados, dialogados, pensados, como nos encontros entre pessoas, entre técnicos e suas instituições. E isso foi ocorrendo desde os encontros na mata nativa, na $O p y$, com as divindades, com os seres da mata, perpassando pelos indígenas, afetando os juruá aliançados favoráveis, como também com os juruá contrários à permanência dos indígenas na área da extinta Fepagro.

Em mais de uma oportunidade, nós juruás, após ter caminhado pela mata nativa, antes de chegar ao centro da tekoá, fomos orientados, por um dos xondaros Mbya que veio recepcionar-nos, para fazer fila e, depois de aguardar alguns minutos, fomos convidados a entrar no pátio central, onde caminhamos até próximo dos indígenas que nos esperavam. Ao chegarmos perto, cada um de nós, individualmente dava mais alguns passos e era recebido pelos indígenas, que levantavam os dois braços, falando a saudação "Aguyjevete" - chegue com a busca da perfeição, com a "verdade verdadeira" -, que respondíamos com a mesma saudação. Tal saudação serve como orientação/desejo para que as pessoas se coloquem abertas para o exercício de um bom diálogo, com palavras ins- 
piradas do coração. Após esta saudação, um grupo de indígenas homens, mulheres e crianças, em harmonia com outros que tocaram a ravé (violino), o mbaracá (chocalho) e o anguapú (tambor), dançaram e cantaram músicas em Mbya-Guarani (Notas do Diário de Campo). Tal ritual nos remete ao que Lazzarato (2006) coloca sobre as relações dialógicas entre pessoas:

A palavra na relação dialógica, tal como Bakhtin a entende, não é uma palavra neutra da língua, vazia de intenções, não habitada pela vida do outro. Aquele que fala recebe a palavra do outro (começando pela sua mãe) com todas as suas entonações, suas afirmações emocionais. Minha própria expressividade encontra a palavra já habitada pela expressividade do outro. Falar significa entrar em uma relação dialógica de apropriação com as palavras do outro, não com o significado das palavras, mas com as expressões, entonações, com as vozes. Falar significa apropriar-se da palavra do outro, ou, como diz Bakhtin, falar leva a trilhar o caminho dentro da própria palavra, que é uma multiplicidade cheia de vozes, entonações, de desejos de outrem (Lazzarato, 2006, p. 163).

Os Mbya-Guarani desta Retomada e de outras áreas indígenas, com frequência fazem manifestações de que devem sempre, ao falar, procurar fazer falas que venham de dentro, falas inspiradas dos ancestrais e de suas divindades. E que não se faça como os juruá muitas vezes fazem, pois estes falariam palavras ao vento, palavras que mentem.

Em uma ocasião, o indígena Alexandre Acosta, xeramói e karai, que estava residindo na terra indígena do Cantagalo, em Viamão-RS, falou das promessas de demarcações de terras feitas por técnicos da Funai e de governos. Dissera que, desde os 18 anos de idade, ouvia falas sobre isso, e que atualmente estava com 58 anos e tais demarcações não aconteceram. Para ele, como para outros indígenas Mbya, os juruá teriam boca grande, falariam palavras ao vento e seriam mentirosos (Heurich et al., 2010). Assim, em encontros com alguns não indígenas, buscam que se forme uma troca dialógica também inspirada, que as falas sejam carregadas de sentido, não sejam palavras vazias ou soltas ao vento.

Poderíamos compreender a Retomada no Yvyrupá como um plano de experiência onde foi sendo tecida, construída, criada uma rede de pessoas e instituições que experimentaram e experimentam processos de subjetivação e agenciamentos que contribuem para a produção de novos possíveis. Nesta rede da Retomada, todos estariam sendo provocados a experimentar retomar alguma coisa, algum afeto, estando sujeitos a alguma afecção que iria marcando cada um. Há, neste acontecimento, neste plano de experiência da Retomada no Yvyrupá, uma miríade de agentes, de atores sociais conectados em redes, que experimentam processos de subjetivação e agenciamentos, e que travam lutas entre linhas de força por abrir possibilidades de mundos outros, de um lado, e, de outro, há linhas de forças que tentam garantir redução de possibilidades e a homogeneização de uma subjetividade capitalística.

\section{Considerações finais}

Os indígenas Mbya-Guarani deram, desde o início de seu movimento, que não foi de busca de alguma terra, mas de um território, fortes indícios de que a área de mata nativa da Mata Atlântica situada em Maquiné-RS, espaço da Retomada no Yvyrupá, reunia as melhores condições para uma tekoá, e que, assim, abria possibilidades para a efetuação de seu modo de vida tradicional ou ancestral, seu tekó ou nhanderekó.

Pareceu-nos que tal acontecimento, experiência, processo, poderia ser conhecido e discutido em diálogo com o que a chamada filosofia da diferença, através do que alguns de seus pensadores associados, aponta como modo de produção de subjetividade ou o que aqui designamos máquina de produção de subjetividade Mbya-Guarani.

Qualidades em rede deste território existencial - sócio-cosmológicas-ambientais-econômicas-xamâmicas - seriam capazes de garantir as melhores condições para a continuidade de um processo de automodelação da sua singularidade como povo indígena. Com as condições de construir a Opy, com a experiência cotidiana de conviver com as matas, as águas, os animais silvestres, as pedras, entre outros elementos e seus demiurgos, poderiam exercitar autocriação de seu tekó.

Estes elementos êmicos conjugados com a possibilidade de continuarem o guatá - o caminhar, a sua intensa mobilidade no mundo criado por suas divindades, poderia estar viabilizando a continuidade de suas buscas pelo aguyjê - perfeição, paraíso - ainda em sua vida terrena. E nesta busca, ao retomar a pos- 
sibilidade de efetuarem seu devir Mbya-Guarani nesta porção da Mata Atlântica, ao conseguirem seguir o guatá de suas divindades e de seus ancestrais, seguiriam o processo de guaranização do mundo, possibilitando a própria continuidade de existência deste mundo criado por Nhanderú Tenondé.

Entendemos ser pertinente pensar que os Mbya-Guarani nos apontaram realizar um tipo de produção de subjetividade própria, que se constitui como uma forma, uma estratégia de resistência ao avanço da subjetivação capitalística - com seu modo-aldeias, circunscrito e sedentário - que a sociedade envolvente lança para capturá-los a um modus de vida que não o de seu povo.

Acreditamos que esta pesquisa e discussão do modo de vida e condições para a efetuação do devir Mbya-Guarani, perpassada pelo tema da produção de subjetividade, com inspiração em pensadores associados à filosofia da diferença e diálogo com outros saberes, pode contribuir para a Psicologia Social, para a Antropologia e outras ciências sociais.

Apesar de também serem potentes, mais do que resultados objetivos, apostamos que esta pesquisa pode abrir campo de análise tanto para a Psicologia Social, como para a antropologia como "ciências" que pesquisam com povos indígenas e povos tradicionais, no que tange ao terreno das composições, das implicações de pesquisadores com seus objetos de pesquisa, como também para o terreno da produção de subjetividade tanto dos não indígenas, afetados pela produção de subjetividade capitalística, como apontam Guattari e Rolnik (1986), como também para pensarmos na produção de subjetividade dos povos tribais e indígenas.

Não só a Psicologia Social e a Antropologia, mas campos de estudos outros, como os relacionados à saúde, o direito, a sociologia, a economia, a ciência política poderiam beneficiar-se no sentido de, ao conhecer e considerar as singularidades Mbya, respeitar e garantir a existência da diferença e o próprio direito à diferença; também, a partir daí, implementar um tipo de revisão nos métodos e concepções destas ciências para com seus objetos de estudo e objetos/sujeitos de suas políticas de atendimentos de seus campos.

E ao final, mas não menos importante, este tipo de pesquisa poderia contribuir para as lutas e para a criação de resistência do povo Mbya e dos povos indígenas em contexto de guerra genocida da sociedade nacional contra seus modos de vida.

\section{Referências}

Associação de Estudos e Projetos com Povos Indígenas e Minoritários - AEPIM. (2017). Retomada com lideranças Mbya Guarani. Porto Alegre, RS: o autor. Recuperado de https://www.facebook.com/aepimrs/videos/755560047932546/?q=aepim\%20\%20retomada\%20mbya\%20guarani\%20maquin\%C3\%A9

Comissão de Terras Guarani Yvyrupá - CGY. (2018). Sobre a CGY. São Paulo, SP: o autor. Recuperado de http://www. yvyrupa.org.br/sobre-a-cgy/

Gobbi, F. S., Baptista, M. M., Printes, R. B., \& Cossio, R. R. (2010). Breves aspectos socioambientais da territorialidade Mbyá-Guarani no Rio Grande do Sul. Porto Alegre, RS: Assembleia Legislativa do Estado do Rio Grande do Sul.

Guattari, F., \& Rolnik, S. (1986). Micropolítica cartografias do desejo. Petrópolis, RJ: Vozes.

Guidoux, S. (2017). Retomada Mbya Guarani em Maquiné. Guidú. Recuperado de https://vimeo.com/204074511

Heurich, G. O., Pradella, L. G. S., Fagundes, L. F. C., Huyer, B. N., Volk, P. M., \& Marquues, R. P. (2010). Presenças impensáveis: Violência estatal contra famílias Guarani no sul do Brasil: Coletivos Guarani no Rio Grande do Sul. Porto Alegre, RS: Assembleia Legislativa do Rio Grande do Sul.

Lazzarato, M. (2006). As revoluções do capitalismo. Rio de Janeiro, RJ: Civilização Brasileira.

Lazzarato, M. (2014). Signos, máquinas, subjetividades. São Paulo, SP: Serviço Social do Comércio.

Passos, E., \& Barros, R. B. (2015). A cartografia como método de pesquisa-intervenção: Pistas do método da cartografia, pesquisa-intervenção e produção de subjetividade. Porto Alegre, RS: Sulina.

Pissolato, E. (2007). A duração da pessoa: Mobilidade, parentesco e xamanismo Mbya Guarani. São Paulo, SP: Universidade Estadual Paulista. 
Psicologia: Ciência e Profissão 2019, 39(n.spe)., e221659,53-66.

Pradella, L. G. S. (2009). Entre os seus e os outros horizonte, mobilidade e cosmopolítica Guarani (Dissertação de mestrado). Universidade Federal do Rio Grande do Sul, Porto Alegre, RS. Recuperado de https://www.lume.ufrgs. $\mathrm{br} / \mathrm{bitstream} /$ handle/10183/18351/000727096.pdf?sequence=1

Sales, M. (2008). Foucault e os modos de subjetivação. Rio de Janeiro, RJ: Universidade do Estado do Rio de Janeiro. Recuperado de https://noboteco.files.wordpress.com/2008/05/foucault-e-os-modos-de-subjetivacao-por-m-sales.pdf

Silva, S. B. (2013). Cosmo-ontológica Mbya-Guarani: Discutindo o estatuto de "objetos" e "recursos naturais". Revista de Arqueologia, 26(1), 42-54. https://doi.org/10.24885/sab.v26il.367

João Maurício Farias

Mestrado em Psicologia Social pela Universidade Federal do Rio Grande do Sul (UFRGS), Porto Alegre - RS. Brasil. Graduado em Ciências Sociais pela UFRGS.

E-mail: jmafarias@hotmail.com

(iD https://orcid.org/0000-0002-3556-9307

Inês Hennigen

Doutora em Psicologia pela Pontifícia Universidade Católica do Rio Grande do Sul (PUCRS), docente do Programa de Pós-graduação em Psicologia Social e Institucional da Universidade Federal do Rio Grande do Sul (UFRGS)

E-mail: ineshennigen@gmail.com

(iD) http://orcid.org/0000-0002-0973-5973

Endereço para envio de correspondência:

Rua Ramiro Barcelos, 2600, sala 413 - CEP: 90.035-003, Porto

Alegre, RS

Recebido 12/04/2019

Aceito 06/05/2019

Received 04/12/2019

Approved 05/06/2019

Recibido 12/04/2019

Aceptado 06/05/2019

Como citar: Farias, J. M., \& Hennigen, I. (2019). A Tekoá Ka'aguy Porã: Espaço ancestral e produção de subjetividade Mbya-Guarani. Psicologia: Ciência e Profissão, 39(n.spe)., 53-66. https://doi.org/10.1590/1982-3703003221659

How to cite: Farias, J. M., \& Hennigen, I. (2019). The Tekoá Ka'aguy Porã: Ancestral Space and Mbya-Guarani Subjectivity Production. Psicologia: Ciência e Profissão, 39(n.spe)., 53-66. https://doi.org/10.1590/1982-3703003221659

Cómo citar: Farias, J. M., \& Hennigen, I. (2019). La Tekoá Ka’aguy Porã: Espacio Ancestral y Producción de Subjetividad Mbya-Guaraní. Psicologia: Ciência e Profissão, 39(n.spe)., 53-66. https://doi.org/10.1590/1982-3703003221659 